\title{
El Rey Costales, personaje de la narrativa oral de Zumpahuacán ${ }^{1}$
}

\author{
King of Sacks, \\ a Character of Zumpahuacan's Oral Narrative
}

\author{
Marco Urdapilleta Muñoz \\ Facultad de Humanidades. \\ Universidad Autónoma del Estado de México. \\ Toluca, México
}

\section{RESUMEN}

El propósito de este artículo es el estudio del Rey Costales, un personaje mítico de la narrativa oral de Zumpahuacán. Su identidad múltiple, proteica, difícil de asir, orientó la investigación hacia el establecimiento de la identidad del personaje. En los relatos se le refiere como un "espíritu" o "alma en pena", pero su conducta permitió tipificarlo como "aire", un género de seres sobrenaturales mesoamericanos Sin embargo, su alto grado de individualización, manifiesto en la conciencia de su condición pagana, así como la falta de vínculos con los fenómenos atmosféricos que inciden en el cultivo hicieron necesarias algunas precisiones. Éstas mostraron que hay un conflicto o ajuste simbólico-religioso entre las creencias cristianas y las vernáculas, y ante todo un reacomodo cultural más vasto que deja ver el proceso de búsqueda de equilibrio en el imaginario colectivo, a partir de las nuevas circunstancias de una comunidad que ha dejado de ser preponderantemente agraria e indígena. Además, la narrativa muestra la creatividad de los habitantes de Zumpahuacán, que proyectan su poder de resignificar experiencias ancladas en el pasado prehispánico a la luz de las vivencias y circunstancias del presente.

Palabras clave: Zumpahuacán, "Aires", Tradición oral, Mito, Enfermedad popular, Nagua.

\section{SUMMARY}

This paper studies the King of Sacks (Rey Costales), a mythical character in Zumpahuacan's oral narrative. This so difficult to grasp character, and its protean condition, oriented the research into determining its identity. According the stories, King of Sacks is kind of a "spirit" or "Banshee", but its behavior is that of an "Air", a Mesoamerican supernatural being. However, its high degree of individualization - as manifested in the consciousness of its pagan status as well as in the lack of links with the atmospheric phenomena affecting crops- required some clarifications. As expected, there is a conflict or symbolic-religious adjustment between Christian beliefs and vernacular beliefs, but above all, a larger cultural realignment revealing the process of looking for balance in collective imagination as a result of a community's new circumstances, no longer

\footnotetext{
${ }^{1}$ Agradezco el indispensable apoyo brindado por Marlen Mendiola. Una versión breve y preliminar de este trabajo fue presentada en el congreso: "Hors normes, retournements, transgressions dans les Amériques", celebrado en el Centro de Investigaciones ETOILL, Montpellier, 24-26 de enero de 2008.
} 
mainly agrarian and indigenous. Beyond this adjustment, the narrative shows the creativity of Zumpahuacan's inhabitants, projecting their ability to shape their experiences anchored in preHispanic past, but in the light of present experiences and circumstances.

Key words: Zumpahuacán, "Airs", Oral Tradition, Myth, Popular Disease, "Nagual".

En una investigación de campo en torno a la narrativa oral del Estado de México efectuada entre septiembre de 2007 y agosto de 2009, se localizó en el municipio de Zumpahuacán al Rey Costales, un ente mítico del cual sólo había una referencia en la Monografía municipal (Casanova 1998: 95-96). Varias razones llevaron al estudio de este personaje: la primera es su importancia cuantitativa, pues 18 de los 61 textos compilados tratan de él; la segunda, su originalidad porque no se encuentra un personaje similar en la región, y, hasta donde se ha podido averiguar, en el Estado; la tercera, la dificultad para aprehender su identidad. La investigación intenta responder a esta cuestión, teniendo muy presente la idea de que estos relatos muestran la faceta creativa de la comunidad que, al transformarse, modela sus creencias tradicionales para sincronizarlas con los nuevos tiempos.

De acuerdo con lo anterior, la hipótesis es que el Rey puede ser comprendido a la luz de un tipo de ser sobrenatural conocido como "aire" o "aire de noche" (respectivamente, en náhuatl, ebecatl, yuhualécatl o yeyécatl) entre los hablantes de lenguas indígenas en el México central y otras comunidades de la misma zona que dejaron su idioma vernáculo de manera masiva hace tres o cuatro generaciones. Pero esta tipificación no es suficiente, porque si bien aclara el sentido de varios actos del Rey no explica su condición de gobernante pagano sobrenatural del poblado. Los "aires", en efecto, adquieren forma humana y otras más asociadas al agua (serpiente, rayo, torbellino, arco iris), y causan las enfermedades populares del tipo "frío" y "espanto", mas no desempeñan el papel de gobernadores sobrenaturales de los humanos ni presentan una vida moral signada por problemas religiosos. También suponemos que esta individualización del Rey responde a los reacomodos socioculturales que ha vivido aceleradamente Zumpahuacán en las últimas cinco o seis décadas, entre los que destacan la sustitución del náhuatl por el español, una mayor presencia del culto oficial católico, un giro en las actividades productivas que incorpora de manera significativa los cultivos no tradicionales (por ejemplo el de la flor) orientados al mercado nacional e internacional, la apertura hacia los imaginarios proyectados por la cultura de masas y la presencia de un cierto tipo de valores inducidos mediante el sistema escolar.

En función de estos planteamientos, la investigación se desarrolló en tres momentos: en el primero, de carácter preliminar, se hizo una cala en torno a la narrativa de Zumpahuacán para determinar las representaciones elaboradas por la tradición oral; en el segundo se estudiaron los relatos del Rey y en el tercero se identificó al personaje como "aire". 


\section{ZUMPAHUACÁN}

El municipio de Zumpahuacán ${ }^{2}$ está ubicado al sur del Estado de México, en la colindancia con los estados de Morelos y Guerrero, a una altura promedio de 2000 m. Cuenta con una población de 16,365 personas, distribuidas en 30 rancherías y comunidades, según el Censo del 2010 (INEGI 2010). El 65\% de la población económicamente activa se dedica a actividades agropecuarias y a ella se orienta el $60 \%$ del territorio del municipio de $200.3 \mathrm{kms}$. De esta superficie, el $68 \%$ no cuenta con riego y, en pequeñas parcelas, se siembra con tecnología incipiente maíz, calabaza y frijol para el autoabastecimiento. En las tierras de regadío se cultiva hortaliza y fruta, destinadas a la casa, mercado local y regional, y sobre todo flor y fresas, que han contribuido a la economía local de manera significativa. Alrededor del $25 \%$ del territorio municipal es de agostadero y los productos que se obtienen (carne, lácteos) se destinan al consumo familiar y al mercado local. De las zonas accidentadas se extrae el agave silvestre para elaborar mezcal en pequeños y rudimentarios alambiques, así como hojas de palma, materia prima de diversos objetos artesanales de consumo regional.

Como sucede en la mayoría de este tipo de comunidades rurales de México, los indicadores socioeconómicos muestran un grado de marginación alto para el municipio. Esta carencia de recursos económicos es el detonante del progresivo movimiento migratorio - en forma temporal o periódica - hacia la ciudad de México y otras poblaciones grandes y medianas del Estado de México y, a partir de los años noventa, también a Estados Unidos. Y si bien las condiciones económicas son difíciles, en relación con décadas anteriores se notan mejoras, según la propia percepción de los habitantes y los censos, particularmente en educación y salud.

La población es casi por completo católica $(98,59 \%)$ por lo cual las festividades y los actos del rito católico desempeñan un papel muy relevante en la vida colectiva, como núcleo de cohesión y construcción de la identidad grupal. Una nota importante, por último, es que el náhuatl o "mexicano", como se le llama en la zona, lo hablan ya sólo 18 personas bilingües.

\section{LA NARRATIVA DE TRADICIÓN ORAL EN ZUMPAHUACÁN}

El conjunto de relatos colectados destaca por la tematización de lo sobrenatural. En esta tesitura sobresalen las breves leyendas en torno a las imágenes del Señor de

\footnotetext{
${ }^{2}$ Antes de la llegada de Cortés el territorio era dominado por los mexicas. Hacia 1530 el pueblo fue encomendado al conquistador Alonso de la Serna con la obligación de prestar servicios a las minas de Zacualpan; pronto decayó por las devastadoras epidemias y sólo se recuperó a principios del XVIII. La participación del pueblo en la revuelta vida política del XIX fue escasa, pero durante la Revolución (1910-1920) la comunidad se mostró afín a los grupos zapatistas; luego hubo una cierta adhesión a la cruzada cristera (1926-1929). El municipio finalmente se pacificó gracias a la institucionalización del poder alrededor del ayuntamiento hacia fines de los años cuarenta e inició un periodo de modernización con la brecha, dirigida a Tenancingo, que abrieron los propios habitantes (1947). A principios de los sesenta llegó la energía eléctrica y el teléfono.
} 
La Ascensión y la Virgen María que manifiestan su deseo de permanecer en el sitio en el que se hallan para que ahí se erijan sus iglesias y capillas. Estas historias poseen gran importancia porque denotan la relación simbólica con la divinidad, particularmente con el santo patrón, hecho que significa, en última instancia, la construcción de un espacio social; esto es, se delimita y da sentido al territorio, y se construyen las referencias de pertenencia que aseguran la identidad del grupo en la historia. También en este agrupamiento están las narraciones que dan cuenta de los milagros, de la voluntad de las imágenes para corregir a los fieles que no siguen las pautas adecuadas durante las festividades religiosas, o bien las que expresan su beneplácito con su fiesta.

Punto de concentración temática es el demonio, que es representado, según la tradición narrativa oral de gran parte del Altiplano Central, como un perro negro y grande con ojos rojos, o como un hombre o charro vestido por completo de negro (el color del atuendo connota poder), o incluso como una mujer seductora. Estos relatos escenifican las tretas del Maligno para engañar a los humanos o recrean su aparición y el gran pavor que suscita, y constituyen advertencias para los borrachos y los mujeriegos; en este sentido, recuerdan los exempla populares de la Colonia. En esta misma esfera temática tienen un lugar destacado las "brujas", caracterizadas, según la tradición regional, como mujeres malvadas que se transforman en guajolotes y fuegos nocturnos.

Otro tipo de relatos son los de las ánimas en pena que, solas o en procesión, vuelven al mundo, y los de encantos, que tematizan campanas, cuevas, tiendas y personas petrificadas. En estos casos las narraciones también siguen patrones muy comunes en gran parte del país. Diferentes a los anteriores son los relatos de la ilama ("vieja," en náhuatl), ser que devora niños, y el de la muerte personificada.

Todas estas historias son consideradas por los narradores como verdaderas (o por lo menos veraces), porque provienen de personas cercanas de toda confianza, sus antepasados o amistades, e incluso los hechos les acontecieron a ellos. Importa resaltar que esta atención hacia los acontecimientos sobrenaturales muestra un entorno cultural en el que permanece un sistema de causalidad no natural de raigambre nahua y católica, capaz incluso de apropiarse de los referentes generados por los medios masivos de comunicación.

Los relatos de ficción o "cuentos", según los lugareños, son tres; los primeros tratan de animales (La zorra y el coyote" y "El mosquito") y el tercero es un cuento maravilloso que refiere una andanza del Rey Costales por la Ciudad de México.

Desde una perspectiva temática, los tipos de relato más importantes de nuestro registro son las leyendas que rememoran los actos que fundan la comunidad como el que cuenta la aparición de algunas figuras sagradas católicas en el lugar; y si se atiende al criterio de la cantidad, la memorata ${ }^{3}$ ocupa el primer puesto.

\footnotetext{
${ }^{3}$ La memorata se construye alrededor de un hecho impactante recordado de manera más o menos inconcreta por la comunidad y que puede ser textualizado cuando alguien le da una forma más acabada (Martos 2007: 25) o bien, asume la forma de anécdota cuando es una experiencia reciente de quien narra. R. Finnegan (1992: 149) equipara la memorata a la personal narrative: "a focus of increasing interest in keeping with current emphases on individual artistry and experience". Por otra parte, Stith Thompson (2001 I: 19) habla de "folklore verbal": supersticiones, costumbres, creencias religiosas, proverbios y adivinanzas.
} 
Los narradores pertenecen a diversos barrios de la cabecera municipal y a dos pueblos muy cercanos a ella; los mayores de 40 años tienen un nivel de escolaridad bajo o incluso son analfabetos; los jóvenes, en cambio, ya han ido a la secundaria y uno cursó el ciclo de educación media superior. Predomina el oficio de campesino $\mathrm{y}$, en el caso de los hombres, si no lo desempeñan, son hijos de campesinos; las mujeres mayores son también hijas o esposas de campesinos. Los narradores más avezados son los de mayor edad, particularmente los que frecuentan poco o nada los libros, pero, en cambio, cultivan con amenidad la plática vespertina.

\section{LA NARRATIVA EN TORNO AL REY COSTALES}

El punto de partida para comprender la identidad del Rey Costales ${ }^{4}$ es una base ordenadora construida como un complejo de relatos (referidos a partir de los núcleos de la acción narrativa) que se articulan en tres secuencias: la primera muestra el advenimiento del Rey; la segunda, sus actos a favor de su pueblo y la tercera, sus agresiones a la comunidad. Este agrupamiento permite percibir el sentido de los relatos de una manera más precisa.

Al margen de esta base quedaron un extenso relato (ver nota 22) debido a que resultó inverosímil para el narrador, que no cree que las montañas tengan vida individualizada, como lo planteaban las antiguas creencias nahuas (Cf. Iwaniszewski 2001: 114-147) y un conjunto de 3 memoratas que describen tangencialmente los actos del Rey, aunque su información resultó relevante en varios momentos de la indagación.

\section{Secuencia I. Aparición del Rey}

Esta secuencia se compone por el relato que refiere el nacimiento del Rey Costales. Sólo una persona narró esta historia y la recibió de sus "abuelos." La presencia en el relato del discurso católico es clara y se combina con creencias de origen nahua. Por supuesto, se percibe una reelaboración muy personal, hecho que jamás descarta la presencia de creencias tradicionales.

Relato $1 .^{5}$ Una versión. El advenimiento del Rey

1.- Ubicación de la comunidad a la cual se va a integrar el Rey Costales.

El narrador, sin mayor afán de precisión, establece que los habitantes del actual pueblo de Zumpahucán provienen del "viejo Zumpahuacán" o Quilocan: "En el año 1500 y tantos fue cuando estuvo la tribu de Zumpahucán viviendo en el Pueblo Viejo [...] ${ }^{6}$. Esta

\footnotetext{
${ }^{4}$ El Rey recibe el nombre de "costales" a causa de su vestimenta confeccionada de costal de izote (yucca aff. jaliscensis), un material que siglos antes era materia prima para la vestimenta rústica. En los relatos, denota pobreza y también extravagancia, porque no sólo no representa la dignidad real, sino que la contradice.

${ }^{5}$ Relato de Víctor Acosta Testela. Campesino de 70 años, sin educación formal; radica en Santa Ana, Zumpahuacán.

${ }^{6} \mathrm{La}$ trascripción de los relatos ha procurado el respeto de la dicción y sintaxis de la versión oral, sólo se suprimieron las muletillas. Las intervenciones en los textos tienen la intención de proporcionar claridad al relato y están señaladas con corchetes.
} 
alusión al pasado remoto de la comunidad mediante una fecha bastante laxa indica que el narrador recogió el dato de oídas, con toda probabilidad fuera de la narrativa tradicional. Se trata de un recurso que pretende aportar credibilidad al relato al situar el momento de la acción antes de la llegada de los españoles.

2.- Se descubre un libro en el que se anuncia que Zumpahuacán va a tener un rey.

Los habitantes del pueblo, gentiles todavía, encuentran una "profecía" en un libro escrito en latín. Esta falta de correspondencia con respecto al tiempo histórico se explica de nuevo por el afán de verosimilitud del narrador. Se tiene presente el viejo prestigio del latín como lengua de lo sagrado y arcano, así como su frecuente asociación con el pasado remoto:

Esos hombres se metieron a una cueva [...] y encontraron un libro, quién sabe qué tamaño, pero un libro. Lo empezaron a ver, esos sabían un poco el latín, empezaron a darse cuenta que esa tribu era el pueblo de Zumpahuacán, de esa tribu venemos nosotros, en el libro venía escrito que iban a tener un rey [...]

3.- Se avisa a la comunidad de la predicción.

En este pasaje, la comunidad recibe la noticia de que va a tener un rey. El narrador construye la imagen de la comunidad a partir del matrimonio, hecho que indica su cercanía con el discurso cristiano, retomado seguramente en las pláticas adoctrinadoras de la parroquia. Por otra parte, es notorio el énfasis en la presencia de la autoridad mediante la figura del "representante", papel bastante común desde hace años en la organización formal de las agrupaciones de tipo civil:

entons esos representantes empezaron a avisar a toda la gente, dijeron a todos, principalmente a las parejas, matrimonios que tenían su esposa: "Va a nacer el rey aquí en nuestra manzana, en nuestra comunidad", les ha de ber dicho el representante, lo respetaban mucho y eran órdenes las que daba.

4.- - La espera del nacimiento del rey.

En esta larga espera se observa la presencia del agua y el remolino, elementos que, como se verá, están asociados al Rey Costales. Alguna reminiscencia hay con el episodio del viaje en canasta de Moisés bebé por el Nilo (Éxodo, 2):

Él taba muy listo al hora que naciera el niño, en la madrugada, en el día, en la noche al hora que fuera, y que así pasaron como diez o quince años buscando ese rey [...] cada niño lo metían en ese cestito y lo aventan una noche allá y así lo dejaban y se venían a dormir ellos, y la cajita toda la noche pasaba dando vueltas ahí en el remolino, todavía existe.

5.--Reconocimiento del rey.

El Rey Costales irrumpe en forma de serpiente; es la señal de su naturaleza diferente y superior:

cuando lo encontraron el que alzó abrió la cajita, vio que estaba ya ahi la señal y habían metido a un niño, un niño tal como lo había echado su madre, ese niño... lo echaron y ya cuando vio que ya era la señal que le había dicho aquel libro, salió y entons les dijo: -Ahora sí, ya llegó nuestro rey [...] no tenga miedo señora ya usted tuvo la dicha y la suerte de ser la madre de nuestro rey, ya aquí viene, aquí lo traimos y no más no se espante. Ni él mismo [el "representante»] sabía qué cosa... Cómo iba a reaccionar, sino que él pensaba que lo que él vio adentro esa era la señal... ¿Qué cosa vio? Era un culebrón que estaba adentro, ese era el rey, una culebra, una víbora grande. 
Esta constitución del Rey como ofidio indica de manera inconfundible la presencia modélica del imaginario indígena, pues no alude en forma alguna al demonio. El valor simbólico de la serpiente apunta hacia las fuerzas atmosféricas (viento y agua).

6.-El Rey Costales deja el pueblo.

De nuevo el Rey se transforma y deja la forma de víbora por la de bebé: "al abrir la cajita pus salta, sale de volada, no más esperó que le abrieran, que se sale, pero cuando salió no era el viborón que había visto, ya era un niño encueradito [...]" Luego muestra su condición sobrenatural y rehúsa a ser tutelado por sus súbditos humanos: "lo iba a agarrar y se quita... era un espíritu [...] todos los querían agarrar y que todos estaban parados, mirando al Rey y no lo dejaban salir ¿eeeh?... como era espíritu no más se hizo y se fue [...]. El rey, como puede observarse, tiene la capacidad de transformar su imagen y es intangible e incorpóreo.

7.-El Rey señala la cueva donde va a vivir.

El Rey hace saber a su gente que va a vivir junto al "pueblo viejo" (el asentamiento prehispánico de Zumpahuacán), en una cueva: “-Mi casa ahi tá [dice el Rey]" y Comenta inmediatamente el narrador: "Yo conozco esa cueva ${ }^{7}$, la conozco, ya me metí, está aquí, en ese cerro grande, enfrente pueblo viejo [...]”. La cueva, más que rusticidad, deja ver su poder, si se sigue la simbología mesoamericana del espacio.

8.-El Rey promete que va a vivir siempre con su pueblo.

El Rey asume su papel de autoridad como gobernante sobrenatural que acompañará siempre a su pueblo: "-Yo soy su rey y voy a vivir hasta la consumación de los siglos con ustedes, voy estar con ustedes [...]".

9.-El Rey se dirige a su morada.

El Rey vuela hacia la cueva que habitará. En este acto el narrador continúa con el proceso de autorizar el relato mediante la ubicación espacial de los hechos en la realidad: "se fue derecho así para acá, les enseñó primero: ahi voy a estar, ahi va ser mi casa y se aventó al voladero, ahi pa arriba, ahi está el río de San Jerónimo, tá un peñononón, ahi se aventó".

\section{Secuencia II. El Rey beneficia a su comunidad}

Esta secuencia la integran relatos bastante heterogéneos que tratan de los actos en los que el Rey es benévolo con sus súbditos.

Relato 2. ${ }^{8}$ El Rey ayudó a edificar la iglesia

1.- Una persona encuentra una biblioteca en una cueva; hay allí un libro en cu-

\footnotetext{
${ }^{7}$ En torno a la cueva en que habita el Rey existe una memorata que cuenta que un grupo encontró 9 cráneos humanos y que en el trayecto hubo percances inexplicables que les pusieron en peligro. Relato de Germán Vázquez, estudiante de secundaria de 15 años de la La Ascensión, Zumpahuacán.

${ }^{8}$ Relato de Donato Salomé Medina Torres, campesino de 70 años sin instrucción formal; radica en La Ascensión, Zumpahuacán.
} 
yas páginas se lee Zumpahuacán, pero, a diferencia del relato anterior, el libro está escrito en español:

Una vez un señor que andaba leñando o paseando, entonces se le presentó una cueva donde estaba una biblioteca; había hartos libros, que ve uno, no le entendió el lenguaje de como estaba escrito y agarra otro, ese sí le entendió, estaba escrito en español: "aquí está el nombre de Zumpahuacán [...]"

2.-Entonces los representantes del pueblo llevan el libro al sacerdote:

Al otro día le enseñaron el libro que traía el fulano y dijo:

- Esta es cosa grande.

Se estaba iniciando el trabajo de la iglesia, juntaron todos los representantes de todo el pueblo, de cada barrio uno, y le dijeron al padrecito:

-Este señor en tal parte encontró este libro; se le apareció una biblioteca, una librería (porque todavía no se usaba el nombre de biblioteca).

3.-El libro contiene las instrucciones que detallan la forma de edificar la iglesia, aunque no está completo: "El padrecito se dio cuenta que en el libro iba el plano de cómo iban a hacer la iglesia; estaban las bardas, pero el techo, o sea las bóvedas, todavía no estaban".

4.-El sacerdote sin mostrar temor, afirma que se reunirá con el Rey, a quien reconoce como autoridad: "-Saben qué, muchachos, señores representantes, tengo que ir allá donde me llama el jefe, el Rey, lo voy a ir a ver; tengo que estar a las doce de la noche y si quieren ir conmigo, vamos, o como quieran".

5.-El encuentro del sacerdote con el Rey está signado por la valentía e inteligencia del religioso: "Y de veras, se fue; los que iban con él vieron que era un bosque tremendón, pero el padre no vio el bosque, sino que él vio como aquí, parejito, limpio. Lo halló al Rey, ya lo taba esperando".

6.-El sacerdote y el Rey llegan a un acuerdo pues éste deseaba apoyar a su comunidad:

El padre y el Rey se pusieron de acuerdo de cómo iba a ser la construcción de la iglesia: - Ira, ta bien que ya te enteres, ya te diste cuenta cómo va a ser el trabajo.

—Sí, ahora yo vine aquí — dijo el padre — para que quedemos en acuerdo como va a ser el trabajo y todo, porque los del pueblo pus quieren trabajar.

-Sí, stá bien.

Quedaron en unos acuerdos buenos que sólo el padre supo.

Se advierte que el Rey, pese a estar descrito como pagano, no obra contra la Iglesia, sino que la respeta, hasta el punto de ser capaz de cooperar y aliarse con su ministro, a quien considera también autoridad del pueblo.

Relato 3. " "La leva"

Este relato es bastante corto y guarda elementos que se anclan en lo histórico, como se advierte en el tema central, la leva obligatoria, muy frecuente en el periodo

\footnotetext{
${ }^{9}$ Relato tomado de la Monografia municipal (Casanova 1998: 94-97). No hay datos del narrador.
} 
revolucionario (1910-1920). El argumento es el siguiente: El Rey marchó a México para solicitar al presidente del país que exhimiera a Zumpahucán del reclutamiento forzado de sus hombres; pero esta petición es en realidad una amenaza, pues si el gobierno no la acepta, "hundirá toda la Ciudad de México". Tal intimidación le parece inapropiada al presidente de México y encarcela al Rey, quien desaparece, no sin antes escribir con letras de oro en la pared de su celda: "Prohibido tocar gente de Zumpahucán", mensaje que se borró luego de haber sido leído por el Presidente y sus ministros. El hecho implícito es que sí hubo reclutamiento forzado y por eso la Ciudad de México se hunde día a día.

\section{Secuencia III. El Rey perjudica a su comunidad}

La mayor parte de los relatos compilados cuentan las diversas agresiones del Rey a su pueblo; estos actos se interpretan como una respuesta al desacato de la voluntad del soberano, la cual debía orientarse a la protección del pueblo. No obstante, la desobediencia está justificada, pues el pueblo juzga que el soberano se ha extralimitado.

La presencia del sustrato cultural nahua se refleja también en el hecho de que el Rey Costales, pese a ser un ente sobrenatural, necesita revitalizarse, alimentarse, para no morir. López Austin (1989 1: 435) explica que para los nahuas prehispánicos los seres sobrenaturales — sin exceptuar a los dioses_ vivían inmersos en un constante ciclo, en el que su vigor y poder menguaban hasta agotarse; para evitarlo necesitaban alimentarse de la fuerza vital de los seres y una de las fuentes más importantes era la energía humana, como lo muestra la avidez de los dioses y otros seres sobrenaturales del panteón mexica.

Relato 4. ${ }^{10}$ El Rey quiere un niño para apropiarse de su energía vital y "renovarse».

De las dos versiones recopiladas se presenta el desarrollo esencial de la más extensa y se señalan las diferencias básicas entre ambas.

1.-El Rey se aparece a Atanasio, el sacristán de la parroquia, en forma de serpiente y luego en forma humana.

vio la cabeza que el enorme culebrón que estaba allí. Y esa cosa que digo que la vio, yo lo comprobé: la cabeza, ese hombre no conocía el miedo, no se espantaba, no, no, taba normal, [...] no se espantaba con nada, era humilde, no agresivo, entocis dice: "Yo voy a ver al padre". Con su sonsera se empieza a bajar con su velita: "Voy a ver al padre, que avisen a la gente que lo vengan a matar, que lo bajen, que lo maten, cómo va estar ahí." Dice que ya iba bajando, pero como al tercer escalón que le habla atrás una persona, le dice:

-Oyes, buen hombre, ven, quiero hablar contigo.

Volteó y tras vio un viejito con traje de costal:

—Quiero hablar contigo [...]

\footnotetext{
${ }^{10}$ La primera es de Silvano Mendiola Mérida, campesino de 43 años con un grado de instrucción primaria que radica en Santa Ana, Zumpahuacán; la segunda de Armando Suárez Bustos, obrero de 19 años con 2 grados de instrucción media superior; vive en San Antonio, Zumpahuacán.
} 
2.-El Rey pide a Atanasio que comunique al pueblo su deseo de "renovarse".

El Rey quiere "renovarse", esto es, proseguir su vida, pero en un cuerpo diferente, "nuevo", pues su energía vital se le agota. Entonces pide a su comunidad un niño de doce años sin bautizar y promete retribuirla con una campana, riqueza en oro y plata, y agua:

Mira, lo que yo quiero es que le digas a tu pueblo que necesito un niño de doce años que no esté bautizado porque me quiero renovar, les voy a entregar la campana que está en pueblo viejo y a cambio quiero un niño de doce años porque me quiero renovar [...] además les doy toda la riqueza que quieran; agua, tesoros, se los pongo encima para que los encuentren $[\ldots]$

No es posible determinar qué sentido tiene la elección de la edad del niño; puede suponerse una significación en el marco de la religión cristiana, debido al evidente valor simbólico del número 12, el número de la elección, el del pueblo de Dios; sin embargo, en el contexto del relato, la interpretación más congruente es la que recurre a la cosmovisión nahua. Es muy probable que el texto se refiera a la edad en que el ser humano adquiere su tonalli, tona, ahora descrita como "alma" (ver nota 15). Un estudio sobre el duelo por un hijo en el poblado vecino de Malinalco (Colín 2005: 516) permitió establecer esta suposición, aunque se señala que no hay uniformidad en torno a esta creencia, pues encontró que la edad para la adquisición de la "Sombra" (tonalli) fluctuaba siempre en un rango inferior. Por otro lado, la condición del niño como no bautizado indica la vinculación del paganismo con el Rey ${ }^{11}$.

3.-Fracaso del intercambio entre el pueblo y el Rey.

El intercambio entre el Rey Costales y el pueblo no llega a buen término. En una de las versiones se señala que no se debió a la negativa de la comunidad de entregar a uno de sus miembros, sino a una conducta irrespetuosa de algunos de los habitantes de Zumpahucán, que fumaban, bromeaban y cargaban dinero en los bolsillos mientras escarbaban en busca de la campana. En la otra versión, la conducta inapropiada no fue de los de Zumpahucán, sino de los de Tonatico, que envidiaron la suerte del poblado vecino: "Por esta envidia se hundió la campana y los pobladores se desesperaron y se vinieron [regresaron]". Además, se cuenta que la campana no sólo ya no afloraba, sino que continuaba enterrándose. Como testimonio gráfico existen dos fotografías de color ocre: en una aparece Atanasio al fondo del socavón y en la otra acostado, boca bajo, sobre la tierra, a un lado de la excavación.

4.-El Rey insiste en su petición y amenaza a Atanasio.

Disgustado por la desobediencia del pueblo, el soberano delega la responsabilidad del intercambio en Atanasio, a quien amenaza con la advertencia de que, en caso de que el pueblo rehúse a su demanda, él será la víctima:

- Hermana, oigo la voz que me dice: "Atanasio escúchame, quiero que trabajes por mí, consigue, por favor, el niño sin bautizar, si no lo haces te voy a llevar en cuerpo y alma" $[\ldots]$

${ }^{11}$ En este sentido hay similitud entre las prácticas sacrificiales efectuadas a fines del siglo XIX en el Monte Tláloc, pues se sacrificaba un niño sin bautizar (Lorente 2010: 524). 
5.-El Rey se "lleva" a Atanasio.

El pueblo no accede a la petición y Atanasio muere y luego desaparece; el Rey se apoderó de él, explica el narrador:

Mi hermano Atanasio a fin de todo falleció porque lo molestaban en el campanario. Lo velábamos cuando se oyeron unas cadenas; después pasó un remolino y se vio un perro grande, como nunca se ven, con los ojos grandes y con una cadena; en ese momento el Rey se llevó a mi hermano en cuerpo y alma; sólo desapareció.

La otra versión cuenta que Atanasio García murió a causa de una enfermedad provocada por el Rey Costales en mayo de 1972 y que su cuerpo no desapareció, sino que fue sepultado.

Relato $5 .{ }^{12}$ El Rey quiere "renovarse".

El Rey, pese a la negativa del pueblo, insiste en "llevarse el alma" de los niños, esta vez sin el consentimiento de la comunidad. Este acto de apropiación es visto como "enfermedad", la cual es muy grave si no se realizan los actos curativos apropiados:

— ¿Sabe qué tiene su niño? ... es un mal espíritu que lo atormenta [...] el Rey; le gustó el cuerpo de su niño para reencarnar y así poder hacer las cosas que él quiere, por eso no da sus cosas, porque él todavía tiene la esperanza de volver a reencarnar en un niño o en una persona, pero más que nada él quiere un niño chico y su hijo le gustó; por eso le necesita tener mucho cuidado porque si no lo cura va llegar el día que en la noche se le va a escapar, se le va a salir y ni va a saber a qui horas se va a echar a correr; necesita cuidarlo.

Relato 6. ${ }^{13} \mathrm{El}$ Rey quiere ser bautizado.

En este relato el Rey desea "heredar sus poderes" a un niño, para luego ser bautizado y morir como cristiano:

- Mira, yo ya me quiero morir, pero quiero que te encargues tú de ver una persona aquí en el pueblo, en todo el pueblo, a ver quien dona su hijo, a ver quien lo dona, yo le voy a pasar el poder a este niño y a mí me van a bautizar.

Entonces que dice:

- Me voy a morir, en la hora que me echen el agua bendita, yo me voy a desaparecer, pero ya el poder lo va a tener el niño, pero sin bautizar y él se va ir a mi lugar y a mi [me] van a enterrar aquí junto a los santos, aquí donde están ustedes, pero ya no me salgo [sin ser] ya hecho un cristiano, porque ahorita no estoy bautizado, no soy un cristiano.

Tal transmisión de los "poderes" implica un intercambio con el pueblo en el que, desde la perspectiva del Rey, la entrega de un niño traerá beneficios a la población porque dichos "poderes" serán depositados en un miembro suyo. El argumento es que los males que ocasiona se deben a su vejez, no a un mero deseo de dañar y que no

\footnotetext{
${ }^{12}$ Relato de Anónimo 1. Tiene 41 años, se ocupa de las labores del hogar y no cuenta con instrucción formal; vive en Santa Ana, Zumpahuacán.

${ }^{13}$ Relato de Apolinar Liborio Díaz García, albañil de 50 años de Santa Ana, Zumpahuacán; estudios formales hasta tercer grado de primaria.
} 
tendrían lugar si tuviera juventud. Sin embargo, para la comunidad este contrato es inaceptable, porque esta especie de inmolación se ofrece a una entidad que no es Dios, aunque tampoco el diablo, pese a que cause daño.

Relato 7. ${ }^{14}$ El Rey y la presa El Pedregal.

Durante la construcción de la presa "El Pedregal", el Rey Costales se hizo presente para exigir una retribución por los cambios que se hacían en sus dominios, los lugares naturales, por supuesto en el marco de relaciones de reciprocidad, lo que implica el reconocimiento de su mando y condición de "dueño" del territorio de Zumpahuacán. Este permiso es, por un lado, una donación ritual y significa reconocimiento y respeto de la dignidad del Rey Costales: "Miren yo voy a querer tantas gallinas o tantos pollos, que me los vengan a enterrar aquí pa que les deje hacer la presa si no, no los voy a dejar, ¿quién les dio permiso?». Al mismo tiempo, no olvida su demanda de un niño para "regenerarse":

- Mira, yo soy el Rey, ya te dije que si me van a dar un niño sin bautizar hacen la presa, si no se las voy a tirar, a nadie han pedido permiso, todo lo que ven aquí es mío, sin mi poder no se hace nada $[. .$.

Esta memorata es una explicación del accidente en el que cuatro personas perecieron ahogadas a los pocos días de haberse inaugurada la presa.

Los relatos de esta última secuencia se reúnen en torno a tres argumentos que explican la conducta perniciosa del Rey:

1.-El Rey, al sentir que su vida se agota, decide recuperar su vigor; para ello necesita nutrirse de la energía vital de un niño, acción que puede realizar con o sin el consentimiento de la comunidad. Sus intentos de apropiación del "alma" de los niños son vistos como enfermedades en las que juega un papel central el "espanto".

2.-El Rey, consciente de que su vida termina, pretende que el pueblo le done un niño sin bautizar para que deposite en él sus "poderes". Desde la perspectiva del Rey, el supuesto de este intercambio es que también favorece a la comunidad, pues sus poderes sobrenaturales son también de su pueblo en la medida en que él se erige en su protector. Sin embargo, desde la perspectiva de la población, estos poderes son sospechosos, ya que no proceden de Dios, aunque tampoco está claro que provengan del demonio. Este conflicto de valoraciones impide el intercambio y el Rey opta entonces por forzar a la comunidad ostentando su posición de jerarca. No obstante, no hay que perder de vista que el propósito último del Rey Costales es dejar la gentilidad y morir enterrado en el camposanto, mas, preso en la lógica de protección de su pueblo no quiere que esos poderes se pierdan con su muerte.

3.-El Rey, en tanto gobernante o "dueño" del territorio donde se asienta Zupahuacán, debe ser tratado como tal. De esta forma, cuando hay una modificación notable

\footnotetext{
${ }^{14}$ Relato de Donato Medina Torres, campesino, 70 años de la Ascensión, Zumpahuacán; sin estudios formales.
} 
del entorno físico (construcción de carreteras o presas) sin una previa petición ritual, el Rey se molesta y castiga a los trasgresores mediante enfermedades frías o accidentes o bien descarga su ira sobre cualquier miembro de la comunidad.

\section{EL REY COSTALES, UN AIRE}

Una vez que se observaron las líneas básicas de la conducta del Rey Costales en la narrativa, toca ahora identificarlo como «aire». En Zupahuacán se le considera como un "espíritu" o un "ánima en pena". Sin embargo, como se verá a continuación, estas denominaciones sustituyen, sin traducir exactamente, conceptos de raigambre nahua.

Es difícil llegar a una definición unívoca de los "aires", puesto que hay variaciones evidentes de región a región, como se observa al comparar las descripciones de Faggetti (1998: 191-196; 2004: 21-38;), Kearny (1971: 69-83), López Austin (1984: 1920), Lupo (2001: 345-356), Maldonado (2001: 397-399), Montoya (1981: 11-17), Redfield (1941: 160-168), Redfield y Villa Rojas (1962: 118-119) y Ruiz Rivera (2001: 80-127, 128-129), aunque es factible fijar algunos rasgos que permiten llegar a su identificación. Antes de iniciar su caracterización resalto de nuevo que es una creencia propia de los grupos indígenas mesoamericanos que permanece entre grupos mestizos que mantienen una forma de vida y comprensión del mundo fincados en elementos culturales indígenas.

En primer lugar los "aires" no son una mera corriente de aire fría, viento o chiflón (Weckman 1994: 545; Kearny 1971: 70-71), sino seres del trasmundo o sobrenaturales ${ }^{15}$, con voluntad propia, invisibles para los seres humanos en condiciones normales de vigilia, aunque en algunos casos están situados en el límite de lo visible; entonces son una emanación vaporosa muy tenue que brota de manantiales, hendiduras en la tierra o de cadáveres, etc. (Cf. Faggetti 2004: 21-26; Morayta 1997: 225; Montoya 1981: 11-14; González 1997: 350-351). No obstante, pueden ser percibidos por el oído o el tacto si se manifiestan como vientos y ser visibles si asumen un cuerpo constituido por "materia pesada", la propia del mundo físico. La forma corpórea que asumen no es permanente y pueden trasladarse a otros cuerpos (humanos, serpientes, etc.) y fenómenos meteorológicos asociados al agua como vientos, torbellinos, rayos, etc. López Austin (1989 I: 429) explica que en el caso de los nahuas esta forma de trasmigración se debe a la capacidad de los seres humanos, vivos o muertos, dioses y animales, de conducir su ibiyotl o nabualli ${ }^{16}$ a otro ser, el llamado ahora nagualismo.

\footnotetext{
${ }^{15}$ Una importante referencia para comprender la naturaleza de los "aires" son las características básicas con las que López Austin (1990: 476-478) acota a los seres sobrenaturales mesoamericanos prehispánicos: a) son imperceptibles para los hombres en situaciones de normalidad; b) poseen facultades para generar cambios y transformaciones en el ámbito perceptible del cosmos, el mundo natural. En este sentido resultan muy peligrosos y el hombre puede influir en sus decisiones mediante ruegos, promesas, compromisos o amenazas; c) se manifestaban en todos los sitios habitados y se hospedaban y circulaban en los seres mundanos, incluido el hombre; d) tienen jerarquía y conforme a ésta variaban sus poderes.

${ }^{16}$ Según los nahuas antiguos y hasta cierto punto los actuales (López Austin 1989 I: 221-262), el ser humano tiene tres entidades anímicas: el tonalli que asienta fundamentalmente en la cabeza y constituye el vigor, el calor del cuerpo humano y el apetito; es de naturaleza caliente y
} 
En algunos casos a los "aires" se les describe como seres antropomorfos muy pequeños y sexuados (Redfield 1941: 165; Montoya 1981: 15; González Montes 1997: 350; Maldonado 2001: 397) con conductas semejantes a las humanas y capacidad de experimentar sensaciones como enojo o diversión e incluso construyen todo un mundo paralelo al humano.

Me parece oportuno recordar aquí, aunque sea marginalmente, la similitud, si no la identidad, del "aire" con el ahuaque, definido éste como un "espíritu pluvial" que reside en el agua, produce los fenómenos meteorológicos (agua, granizo, lluvia, truenos) y que captura el "espíritu" del ser humano cuando éste se introduce en sus dominios - cuerpos de agua, manantiales.

Por su origen, los "aires" son una emanación de los muertos o de meras fuerzas de naturaleza fría; en este sentido son "seres subterráneos" (López Austin 1984: 20) asociados simbólicamente al agua. De ahí que se les caracterice por la polaridad fría y oscura (Lupo 2001: 355).

Viven en los lugares no ocupados por personas (cerros, cuevas, barrancas, árboles, ríos, manantiales) y los tienen como un territorio en el que ejercen su dominio y autoridad (Álvarez 1987:122); también su morada puede ser el lugar donde murió la persona y pueden trasladarse a los lugares donde viven los seres humanos.

Según su manera de actuar, los "aires" reciben el nombre de "aires buenos," cuando permiten, mediante el buen tiempo, una cosecha abundante; los "aires malos" son los que provocan algún fenómeno atmosférico asociado al agua (granizo, escarcha, torbellinos, tolvaneras, remolino de agua) que estropea los sembradíos; o los que se introducen en el cuerpo de los humanos y lo enferman. Estos peligrosos y omnipresentes seres atacan cuando son perturbados por las personas que transitan por los lugares donde moran — parajes deshabitados o el lugar donde murió alguien y espacios donde hay agua - o cuando los humanos están débiles o "espantados", o incluso a instancias de los hechiceros que los dirigen hacia una persona.

El malestar de la "enfermedad de aire" es del régimen frío-húmedo ${ }^{17}$ (Morayta 1997: 225; Lupo 2001: 354) y los síntomas característicos son vómito, mareo, palidez, pérdida de apetito. El "espanto" o "Susto" es un estado de debilidad caracterizado por la "pérdida del alma" o "tona" —o tonalli entre los nahuas prehispánicos (López Austin 1989: I, 223-252) — que se origina por una impresión fuerte y repentina, un "shock emotivo", causada casi siempre por seres sobrenaturales y animales

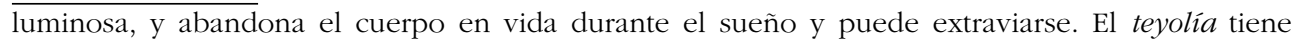
su sede en el corazón y en él radican las facultades psíquicas (memoria, razonamiento, voluntad); es de naturaleza caliente y abandona el cuerpo sólo cuando éste deja de existir y se va a las moradas de los muertos. El ibíyotl tiene su sede en el hígado y sus funciones están vinculadas a la pasión y al sentimiento, así como al vigor. Algunos seres tienen la facultad de externarlo (nagualismo), o bien sale como emanaciones de los vivos, en determinadas circunstancias, o muertos. También recibe el nombre de nabualli y, tras la muerte, yuhualécatl o "aire de noche".

${ }^{17}$ López Austin (1984: 18) sostiene que "las enfermedades frías, por regla general, se producen por la intrusión de la calidad fría, que puede llegar al organismo por medio de una corriente fría, en el momento en que el hombre se encuentra débil, o por la ingestión de algún alimento frío. Al inmoderado consumo de este tipo de comidas se atribuye, por ejemplo, un tipo de diarrea. Estas enfermedades se presentan como fenómenos de incapacidad, que aminoran o anulan las funciones sensoriales o motoras. No son exteriormente notables y se hacen patentes por el dolor o la inmovilidad". 
(Signorini y Lupo 1989: 83; Faggetti 1998: 99). Sus síntomas son: debilidad general, falta de apetito, somnolencia, inquietud durante el sueño, pesadillas, fiebre, escalofríos, vómito y "tristeza" y, en el caso de los niños - los más propensos al susto a causa de su "debilidad"-, el llanto constante sin razón evidente y un estado permanente de apatía. Esta enfermedad puede llevar a la muerte si no se toman las medidas adecuadas.

Esta constante interacción de los "aires" con el ser humano corresponde a la idea de un vasto proceso que López Austin (1990: 478) describió, pensando en el trasmundo indígena prehispánico, como una "generación y regeneración del cosmos". En este movimiento, como cualquier ser vivo, los "aires" actúan para obtener la materia vital, y su principal sustento es el hombre; de él pueden tomar, en el caso más grave, hasta el "alma". Debido a esta conducta casi siempre imprevisible y adversa a los humanos, "aire" equivale con mucha frecuencia a "mal aire" (Signorini y Lupo 1989: 83).

Pero el ser humano no se encuentra inerme, porque los "aires", seres con voluntad, pueden ser arrostrados y controlados mediante prácticas preventivas y curativas de carácter ritual (súplicas, ofrecimientos, promesas, insultos, permisos, rezos etc.) y no ritual -física-, que consiste en una limpia con yerbas "calientes", o "yerbas de aire", mezcladas con alcanfor o alcohol. En ambos casos se pretende la expulsión del ente que entró en la persona. Además, en el caso de los "aires buenos", se realizan actos de culto, dirigidos a propiciar el buen tiempo, en espacios consagrados como montañas (casi siempre en la parte alta, donde se detienen las nubes), cuevas y manantiales (Maldonado 2001: 399).

También es importante señalar que en algunos casos a los "aires buenos" se les clasifica de acuerdo a una jerarquía de poder. En Atla, un poblado nahua de la región serrana de Puebla, Montoya (1981: 15) registra una escala basada en la efectividad de los poderes de los aires, y en Ocotepec, Morelos, se percibe esta gradación en la idea de que existe un "gran aire" protector (Morayta 1997: 229).

El carácter benéfico o pernicioso de los "aires" recuerda la ambivalencia moral de las entidades sobrenaturales nahuas antiguas y actuales; sin duda por ello no están asociadas por completo al demonio, aunque cuando dañan se les conjura también con el arsenal cristiano.

Por último, debido a su importancia en el imaginario indígena contemporáneo, Romero (2006: 84-85) propone la denominación de "aires" para todos los seres del trasmundo —o como ella lo llama- el "mundo otro" de matriz indígena mesoamericana.

Una vez caracterizada la figura del "aire", se establecieron algunos puntos de contacto que permiten la identificación del Rey Costales con este tipo de ente:

a) es un ser sobrenatural personalizado.

b) habita en una cueva.

c) se ostenta como "dueño" y al mismo tiempo como guardián de un territorio porque lo controla y puede perjudicar a quien lo perturba cuando se invade su espacio sin previo consentimiento. Pero también entre sus atributos de dueño está el de dispensar riquezas: una campana de oro, dinero, agua.

d) no es una entidad intrínsecamente maléfica y puede favorecer a los humanos siempre y cuando reconozcan su preeminencia y la acaten mediante diversas formas de conducta ritual y de intercambio: promesas, compromisos, ruegos, ofrendas, pleitesía, etc. 
e) daña a los humanos con enfermedades del régimen frío- húmedo y provoca "espanto". Desde la perspectiva del Rey la enfermedad es una apropiación de la energía necesaria para vivir, es alimentación. Se apropia del "alma" (tonalli, tona) del individuo.

f) es un ser proteico cuya fisonomía predominante es la humana.

Si bien los elementos señalados son suficientes para identificar al Rey Costales como un "aire", existe un conjunto de diferencias perceptibles que es necesario observar para comprender su identidad y significado de su conducta. Así, el Rey

a) está desvinculado del ciclo agrario, porque no se le invoca para la protección de los sembradíos; aunque se advierte su antiguo papel productivo en dos hechos: tiene como morada una cueva y su versátil fisonomía está asociada con el agua en la simbología mesoamericana: es remolino de viento y agua ("cola"), arco iris, rayo y serpiente ${ }^{18}$.

b) es gobernante, rey, de Zumpahuacán. En este papel traduce su condición de protector de Zumpahuacán, propia de los "aires buenos", función que proviene, al parecer, de la creencia en el "gran aire" protector de los pueblos, como lo observó Morayta (1997) en Ocotepec ${ }^{19}$.

c) provoca accidentes — no sólo enfermedades- que se interpretan como reparación de un agravio motivado por la invasión de su territorio.

d) no puede ser utilizado para dañar a terceros mediante la hechicería, a diferencia del común de los aires.

e) con frecuencia sus víctimas son los niños.

f) en su fisonomía humana su talla es excepcionalmente grande, excepto en un relato, pero no tiene el tamaño de un duende.

g) Posee una constitución moral particular, acentuada por su deseo de apoyar a la Iglesia y convertirse al cristianismo antes de morir.

Algunas de las diferencias de la conducta del Rey con respecto al patrón de "aire" que se estableció se explican por los cambios socioculturales de Zumpahuacán, que ya no es un poblado aislado ni por entero campesino, ni mucho menos indígena. En este nuevo contexto el Rey, como "aire", ya no está vinculado productivamente al ciclo agrario tradicional cuyo núcleo es el cultivo del maíz, pues ya no interviene en los eventos climáticos que benefician o perjudican los sembradíos; aunque conserva el papel de vigilante, de regulador de las actividades humanas en el medio natural, así como un recubrimiento simbólico que lo vincula inequívocamente al agua, ele-

\footnotetext{
${ }^{18}$ Es oportuno tener presente que los dos fenómenos meteorológicos enunciados en primer lugar tienen como factor común el giro. En el pensamiento nahua antiguo los dioses hacían llegar sus fuerzas a la superficie terrestre dándoles un movimiento giratorio (López Austin 1989: I, 228). En la actualidad, debido a su capacidad de para dañar, a estos fenómenos se les puede vincular con el demonio. Por su parte, el rayo y el arcoíris están asociados a la serpiente debido a que se considera que, de diversa forma, la reproducen simbólicamente. Además, al ofidio se le vincula no sólo al agua, sino también a las fuerzas ctónicas. Y, debido a que habita las cuevas, su asociación con el inframundo y sus riquezas es inevitable (Hayden 1981: 27-28).

19 Este "aire" protector vive en una cueva que se considera como un respiradero de la tierra. Desde ahí sale con tal fuerza que desbarata las tormentas más fuertes, aunque también puede ser guiado para causar daños cuando los brujos llevan ahí monigotes con alfileres clavados y otros objetos para sus funestos deseos.
} 
mento cuya posesión denota poder en un contexto de escasez. De esta forma, como dueño del territorio, es capaz de manifestar su disgusto y actuar en contra de quienes pretenden modificar con presas y caminos el entorno natural; es decir, actúa contra quienes pretenden modificar el equilibrio natural. Algunos miembros de la comunidad interpretan esta conducta como la oposición del Rey al "progreso"; otros señalan, siguiendo la tradición ritual, que no es un obstáculo si antes de modificar el entorno se obtiene su aquiescencia. Sin embargo, es claro que la faceta nociva del Rey se incrementa porque también provoca accidentes, no sólo enfermedades, como sugiere la costumbre. Este hecho deja ver una modificación de la función del Rey que, considerado como "aire", pierde su faceta productora positiva a favor del predominio de la negativa, que causa daño y temor.

Otra diferencia del Rey con respecto al patrón de "aires" radica en su mayor grado de individualización, pues posee una conciencia religiosa y moral. En este sentido, la narrativa compilada muestra una instantánea del largo proceso de construcción de la identidad religiosa de Zumpahuacán, esto es, un ajuste entre las creencias religiosas indígenas y las cristianas. La evangelización destruyó el culto oficial en Mesoamérica, pero no logró erradicar las creencias religiosas ligadas al ciclo agrario (Florescano 1999: 314-315; López Austin 1973: 76-77). Contamos con varios testimonios de esta encrucijada en Zumpahuacán, como el del extirpador de idolatrías Pedro Ponce de León (2008) a principios del XVII, el del sacerdote Canuto Flores (1909), designado como cura del "pueblo de indios" de Zumpahuacán en 1898, y el de Víctor Acosta, quien señala que los más viejos creían que en las montañas que rodeaban Zumpahuacán habitaban seres poderosos.

Esta individualización y otros de los rasgos señalados permiten suponer estrictamente en el plano de la conjetura, pues no hay documentación, sino interpretación de los actos y símbolos de los relatos, que el Rey Costales pudiera constituir una reminiscencia de un dios tutelar prehispánico de Zumpahuacán, el capultéotl ${ }^{20}$. La suposición se basa en algunas características del Rey: tiene un papel de protector, ostenta una jerarquía superior, obra como dueño de un territorio, posee poderes sobrenaturales como el de la capacidad de transformarse; habita en la cueva ${ }^{21}$ de un cerro cercano al asentamiento prehispánico de la comunidad y puede conceder riquezas y agua, aunque, como ya se señaló, perdió sus atributos pluviales. Adelantando en esta especulación, se puede conjeturar incluso que el Rey Costales es la rememoración de una entidad sobrenatural que no fue asimilada, como sucedió con frecuencia a raíz de la implantación del catolicismo en muchos pueblos de Mesoamérica, a la figura del santo epónimo de la comunidad (Cf. López Austin 1973: 7677; Báez-Jorge 1998: 236-242). Es posible pensar entonces que, al quedar al margen de esta transformación simbólica, fue reelaborado, asimilándolo a la figura de "aire».

\footnotetext{
${ }^{20}$ El capultéotl (López Austin 1989: I, 75-81) moraba en un cerro cercano a su comunidad (con frecuencia en una cueva) y estaba ligado míticamente, desde sus orígenes, a ella; desempeñaba un papel de primer orden en cuanto protector al que había que dar culto para obtener sus beneficios y se consideraba que de él dependía la estabilidad del grupo y de manera particular su alimentación, porque actuaba como dios pluvial.

${ }^{21}$ Como ya se señaló, en Mesoamérica las cuevas, hogar de seres sobrenaturales, son un espacio simbólico de contacto con el mundo sobrenatural y el inframundo, pero también simbolizan la relación con los antepasados, el origen y la legitimación de los grupos étnicos.
} 
Ya de vuelta a terreno firme, se percibe que el Rey rebasa en diversos aspectos la figura del "aire" tradicional, conforme se planteó, puesto que se le considera ya como "espíritu" o "alma en pena" o "ánima en pena". La palabra "espíritu" designa para los narradores a las entidades que cuentan con algún tipo de capacidad o cualidad que rebasa las facultades humanas y por ello provocan un gran temor entre las personas, como dice Higinio Mendiola Vázquez ${ }^{22}$ :

Yo creo que sí existen algunas cosas de espíritus, como dice el dicho... o no sé, sabrá Dios cómo será, pero sí los hay porque yo también he visto eso, es muy feo [ ...] por eso digo que sí existe eso de los espíritus, pero no sabemos ni que cosa son; ni modo de agarrarlos, saludarlos, ¿no?, son cosa espantosa.

En conclusión, estos relatos expresan la memoria soterrada de un complejo y antiguo conflicto simbólico- religioso de Zumpahuacán entre las creencias cristianas que se sobrepusieron a las vernáculas. Pero no sólo manifiesta un conflicto religioso, sino también un reacomodo cultural más vasto, que deja ver el proceso de búsqueda de equilibrio en el imaginario colectivo a partir de las nuevas circunstancias de una comunidad que ha dejado de ser preponderantemente agraria y que a su manera responde — también narrativamente- a los estímulos que llegan de otras latitudes con sus propias herramientas interpretativas y referentes culturales. Así, por ejemplo, en el relato en el que las montañas adquieren vida y personalidad ${ }^{23}$, la creencia propia de los antiguos mesoamericanos es ahora considerada como ficción por los narradores. En cambio entre los jóvenes, ya educados en sistemas escolares y tratados en los centros médicos oficiales, existe la creencia bastante extendida, y expresada no sin titubeos, en el Rey; sin embargo, su percepción no es la de la generación de sus padres, como lo deja ver el relato en el cual el Rey organizó una fiesta en su cueva:

Iban unos chavos por el llano y que encontraron a otro chavo, pero ese chavo era el Rey, el rey Costales. Supuestamente él los invitó a una fiesta que iba haber en su casa, que dice: "Lléguenme a las ocho". Entons ellos, que eran bien desmadrozos, hacían desmadres, iban a donde sea encantados de la vida, se les hizo más padre que iba a ser por allá, en Pueblo Viejo, no sé... como más peligro... entonces fueron, llegaron donde les dijo él:

-No pues se van a tal, y a tal, y allí llegan.

\footnotetext{
${ }^{22}$ Campesino, 72 años, sin educación formal, originario de Santa Ana, Zumpahuacán.

${ }^{23}$ Este relato tiene dos versiones: la primera, la que se toma como referencia, es de Víctor Acosta, y la segunda proviene de la Monografía municipal (Casanova 1998: 95). Este es el argumento del relato: El rey de México, deseoso de colocar una gran campana en la catedral, solicitó ayuda a otros soberanos amigos, mas ninguno logró apostarla en el campanario. Entonces acudió el señor de Zumpahucán, cuya rústica ropa, poco apropiada para su dignidad, le valió más bien la cárcel. No obstante el soberano de México le dio una oportunidad al de Zumpahuacán que auxiliado por un fuerte viento plantó la campana en la torre. Pero la retribución acordada, la mano de la hija del rey de México, fue escamoteada por su padre porque su par le parecía muy pobre en riquezas e inteligencia. Entonces cortó el pelo a la muchacha y la escondió entre la servidumbre, pero el Rey Costales la identificó y se dirigió con ella a sus dominios. Disgustado, el jerarca de México trató de recuperarla y mandó a su ejército a detener al forastero. El Rey utilizó una serie de recursos mágicos para escabullirse y, ya a salvo, la mujer expresa su disgusto por el aspecto de Zumpahuacán; entonces se convirtió en La Malinche, una montaña cercana al poblado. Vale notar que al pie de esta brota un manantial cuya forma recuerda a la de la vagina.
} 
Llegaron al cabo:

— ¿Dónde está?, ¿đónde nos vamos a ver?, ¿dónde va ser la fiesta o qué?

Pues nada más lo único que había era una cueva y la entrada a una cueva, así, chiquita... Pasaron encogidos mientras se metían, entrando ya caminabas normal, parado, se metieron... total...

Adentro todo era muy lujoso, todo era de oro. Estuvieron en la fiesta, encontraron al chavo ese, el que era el rey. Pasó la fiesta, pero su ambición [de los jóvenes] era tan grande [que se] llevaron, no sé... una mochila, creo, y echaron todo lo que encontraban, cuanto se veía de oro. Ya se venían muy felices porque ya traían mucho oro y se iban a volver ricos. Saliendo de la cueva iban platicando: "vamos a venderlo", y bueno, venían platicando hasta lo que iban a hacer. Cuando pasaron el río o el pueblo, no sé qué, a donde echaron lo de oro iban saliendo víboras o sapos... que no era oro. Entonces ellos se espantaron y que se acordaron. Ya no volvieron a robar, bueno a traerse lo que no les pertenece ${ }^{24}$.

Se advierte un salto inmenso en la comprensión y representación del Rey, que ahora pierde su condición destructiva y sacra; en cambio es "rico" (y no en agua), joven y no causa enfermedades; sin embargo posee rasgos sobrenaturales. Por otro lado, puede verse que la cueva ya no es el respiradero de la tierra que conecta al inframundo y, por tanto, el sitio adecuado para los rituales sacros, sino una habitación que no deja de parecer influida por la idea del encanto.

Ahora, al preguntarnos la razón por la cual no se ha dejado de creer en el Rey Costales, pese a que en determinados sectores de Zumpahuacán se le considera como una vana superstición propia de personas "ignorantes", se debe a la permanencia en el pueblo de una causalidad mágica de raigambre indígena que es capaz de modelar la recepción de imágenes como la de los duendes y asimilarlas a los "aires", tanto en jóvenes adiestrados en escuelas como en adultos sin educación formal. Por supuesto también la causalidad mágica de cuño católico tiene importancia y juntas articulan un campo de lo sobrenatural que irrumpe en el fluir normal del tiempo cotidiano, que genera el miedo a la enfermedad y las prácticas para su interpretación y combate. Pero las formas de sobreponerse a este pathos no necesariamente están en abierta contradicción con las prácticas modernas, como, por ejemplo, las médicas. Es preciso recordar que la medicina contemporánea ya otorga un peso específico a los "síndromes de filiación cultural" en la etiología de las enfermedades como el "susto" o "espanto" (Cf. Faggetti 2004).

Por último, es muy importante tener presente que la pervivencia y transformación del Rey Costales es una clara muestra de la capacidad, no sólo adaptativa, sino también creativa, de los habitantes de Zumpahuacán que proyectan a través del relato su poder de resignificar experiencias de un pasado indígena a la luz de las vivencias y circunstancias del presente.

\section{BIBLIOGRAFÍA CITADA}

Álvarez Heydenreich, L. 1987. La enfermedad y la cosmovisión en Hueyapan, Morelos. México: Instituto Nacional Indigenista.

Báez-Jorge, F. 1998. Entre los naguales y los santos. Religión popular y ejercicio clerical en el México indigena. Xalapa: Universidad Veracruzana.

\footnotetext{
${ }^{24}$ Relato anónimo, 15 años, estudiante de secundaria, originario de Santa Ana, Zumpahuacán.
} 
Casanova, L. 1998. Zumpahuacán. Monografía municipal. Toluca: Instituto Mexiquense de Cultura. Colín, A. 2005. Antropología y psicoanálisis. Un diálogo posible a propósito del duelo por un bijo en Malinalco. Toluca: Universidad Autónoma del Estado de México.

Faggetti, A. 1998. Tetzonhuhue. El simbolismo del cuerpo y la naturaleza. Puebla: Benemérita Universidad Autónoma de Puebla.

Faggetti, A. 2004. Sindromes de filiación cultural. Conocimiento y práctica de los médicos tradicionales en cinco de los Hospitales Integrales con Medicina Tradicional del Estado de Puebla. Puebla: Gobierno del Estado de Puebla.

Finnegan, R. 1992. Oral traditions and verbal arts. A guide to research practices. Londres: Routledge.

Flores, C. 1909. "Modo de elegir esposa entre los indios naturales del pueblo de San Gaspar, Estado de México". Anales del Museo Nacional de Arqueología, Historia y Etnología I, tercera época: 5966.

Florescano, E 1999. Memoria indígena. México: Taurus.

González Montes, S. 1997. "Pensamiento y ritual de los ahuizotes de Xalatlaco, en el Valle de Toluca", en Albores, B. y Broda, J., Graniceros y meteorología indigenas de Mesoamérica: 313-359. Zinacantepec: El Colegio Mexiquense, Universidad Nacional Autónoma de México.

Hayden, D. 1981. "Caves, gods and myths: world-view and planning in Teotihuacan", en Benson, E. (ed.), Dumbarton oaks conference on Mesoamerican sites and world-views: 1-40. Washington: Trustees for Harvard University.

Instituto Nacional de Estadística, Geografía e Informática (INEGI) 2010. XIII Censo general de población. México: INEGI.

Iwaniszewki, S. 2001. “'Las montañas tienen género'. Apuntes para el análisis de los sitios rituales en el Iztaccíhuatl y Popocatépetl", en Broda, J., Iwaniszewski, S. y Montero, A. (eds.), La montaña en el paisaje ritual: 114-147. México: Universidad Nacional Autónoma de México, Instituto Nacional de Antropología e Historia.

Kearny, M. 1971. Los vientos de Ixtepeji. Concepción del mundo y estructura social de un pueblo zapoteco. México: Instituto Indigenista Interamericano.

López Austin, A. 1973. Hombre-Dios. Religión y politica en el mundo nábuatl. México: Universidad Nacional Autónoma de México.

López Austin, A 1984. Textos de medicina nábuatl. México: Universidad Nacional Autónoma de México.

López Austin, A. 1989. Cuerpo humano e ideología. Las concepciones de los antiguos nabuas, 2 vols. México: Universidad Nacional Autónoma de México.

López Austin, A. 1990. "Tamoachan y Tlalocan. La cosmovisión en Mesoamérica", en Lombardo, S. (ed.), Temas mesoamericanos: 476-488. México: Instituto Nacional de Antropología e Historia, Consejo Nacional para la Cultura y las Artes.

Lorente, D. 2010. "El remolino actuado: Etnografía contemporánea del Monte Tláloc". Revista de Dialectología y Tradiciones Populares LXV (2): 519-546.

Lupo, A. 2001. "La cosmovisión de los nahuas de la Sierra de Puebla", en Broda, J. y Báez-Jorge, F. (eds.), Cosmovisión, ritual e identidad de los pueblos indígenas de México: 239-252. México: Consejo Nacional para la Cultura y las Artes, Fondo de Cultura Económica.

Maldonado, D. 2001. "Cerros y volcanes que se invocan en el culto a los 'aires' en Coatetelco", en Broda, J., Iwaniszewski, S. y Montero, A. (eds.), La montaña en el paisaje ritual: 382-406. México: Universidad Nacional Autónoma de México, Instituto Nacional de Antropología e Historia.

Martos, E. 2007. Cuentos y leyendas tradicionales. Teoria textos y didáctica. Cuenca: Universidad de Castilla-La Mancha.

Montoya Briones, J. 1981. Significado de los aires en la cultura indigena. México: Instituto Nacional de Antropología e Historia.

Morayta, M. 1997. "La tradición de los aires en una comunidad del norte del estado de Morelos: Ocotepec", en Albores, B. y Broda, J., Graniceros y meteorología indígenas de Mesoamérica: 217232. Zinacantepec: El Colegio Mexiquense, Universidad Nacional Autónoma de México.

Ponce de León, P. 2008. "Breve relación de los dioses y ritos de la gentilidad por don Pedro Ponce beneficiado que fue del partido de Zumpahuacán", en AA. VV., Hechicerías e idolatrías del México Antiguo: 26-41. México: Consejo Nacional para la Cultura y las Artes. 
Romero López, L. 2006. Cosmovisión, cuerpo y enfermedad: El espanto entre los nabuas de Tlacotepec de Diaz, Puebla. México: Instituto Nacional de Antropología e Historia.

Redfield, R. 1941. Tepoztlán, a mexican village. Chicago: The University of Chicago Press.

Redfield, R. y Villa Rojas, A. 1962. Chan Kom, a mayan village. Chicago: The University of Chicago Press.

Ruiz Rivera, C. 2001. San Andrés de la Cal, culto a los señores del tiempo en rituales agrarios: historia y antropología de un pueblo de Tepoztlán. Cuernavaca: Universidad Autónoma del Estado de Morelos.

Signorini, I. y Lupo, A. 1989. Los tres ejes de la vida. Almas, cuerpo y enfermedad entre los nabuas de la Sierra de Puebla. Xalapa: Universidad Veracruzana.

Thompson, S. 2001. Mofif-index of folk-literature, 7 vols. Bloomington e Indianápolis: The Indiana University Press.

Weckman, L. 1994. La herencia medieval de México. México: El Colegio de México-Fondo de Cultura Económica.

Fecha de recepción: 30 de marzo de 2011

Fecha de aceptación: 20 de abril de 2012 